NoTE

\title{
Acute Onset and Worsening of Diabetes Concurrent with Administration of Statins
}

\author{
ChIE OHMURA, HIROTAKa WATADA, TAKAHISA HIROSE, YASUSHI TANAKA AND RYUZO KAWAMORI \\ Department of Medicine, Metabolism and Endocrinology, Juntendo University School of Medicine, 2-1-1 Hongo, Bunkyo-ku, Tokyo \\ 113-8421, Japan
}

\begin{abstract}
We report a patient in whom the administration of HMG CoA reductase inhibitors (statins) might have triggered the onset and worsening of diabetes. The patient was a 48-year-old Japanese man who underwent annual medical examination but had never been told of hyperglycemia. Four months after the commencement of atorvastatin $(10 \mathrm{mg} /$ day) treatment, a diagnosis of diabetes mellitus was made from his typical symptoms of hyperglycemia, postprandial plasma glucose level of $29.8 \mathrm{mmol} / 1$ and $\mathrm{HbA}_{1 \mathrm{c}}$ of $11.5 \%$. After 2 months of insulin therapy and 3 months after the cessation of atorvastatin, almost complete resolution of diabetes was observed. During the subsequent 3 months, diet therapy alone was sufficient to control blood glucose level. Then, we prescribed pravastatin ( $20 \mathrm{mg} /$ day). During the subsequent 3 months, $\mathrm{HbA}_{1 \mathrm{c}}$ was gradually increased. However, after discontinuation of pravastatin, $\mathrm{HbA}_{1 \mathrm{c}}$ was gradually decreased. In the general population, statin does not seem to have critical adverse effects on glucose tolerance, but it may uncommonly modify the natural course of the development of diabetes in certain patients.
\end{abstract}

Key words: Atorvastatin, Pravastatin, HMG-CoA reductase inhibitor, Hyperlipidemia, Type 2 diabetes

(Endocrine Journal 52: 369-372, 2005)

PATIENTS with type 2 diabetes mellitus often have hypercholesterolemia and thus are frequently treated with HMG CoA reductase inhibitors (statins). The efficacy of statins in lowering serum cholesterol concentration is well established [1-3]. The results of the Cholesterol and Recurrent Events (CARE) trial [1], Scandinavian Simvastatin Survival Study (4S) [2], and Collaborative Atorvastatin Diabetes Study (CARDS) [4] confirm the usefulness of statins in reducing cardiovascular events in type 2 diabetic patients with hyperlipidemia.

In addition to their hypocholesterolemic effect, statins are also known to possess pleiotropic effect such as reducing the expression of various adhesion molecules, inhibition of the proliferation and migration of vascu-

Received: January 17, 2005

Accepted: March 7, 2005

Correspondence to: Hirotaka WATADA, M.D., Ph.D., Department of Medicine, Metabolism and Endocrinology, Juntendo University School of Medicine, 2-1-1 Hongo, Bunkyoku, Tokyo 113-8421, Japan lar smooth muscle cells $[5,6]$, anti-thrombotic effects [7], and suppression of inflammation [8]. The mechanism of the pleiotropic effect of statins seems to be mainly exerted by the reduction of intermediates of the mevalonate pathway. The mevalonate pathway leads to the formation of isoprenoids, such as geranylgeraniol, which are important for the post-translational modification of several proteins. Small GTP-binding proteins such as RhoA, Rac, amd $\mathrm{Cdc} 42$ are among them. It has been widely known that these molecules are important for cell proliferation and cell adhesion. Thus, the reduction of the post-translational modification of small GTP-binding proteins by statins can at least partly account for the beneficial pleiotropic effect. However, considering such a mechanism, statins might also exert the adverse effect. In fact, Yada et al. previously reported that atorvastatin can inhibit glucoseinduced insulin secretion by blocking L-type $\mathrm{Ca}^{2+}$ channels in pancreatic $\beta$ cells [9]. Further, Chamberlain reported that inhibition of isoprenoid biosynthesis by lovastatin can deteriorate insulin responsive glucose uptake by down-regulation of glucose transporter 4 in 
3T3-L1 adipocytes [10]. Accordingly, these experimental data suggests that statins might deteriorate glucose tolerance.

Here, we report a patient in whom the administration of statins was concurrent with the onset and worsening of diabetes.

\section{Case Report}

The patient was a 48-year-old Japanese man who underwent annual medical examination but had never been told of hyperglycemia. His life style, including eating habits and physical activity, had not changed over the last 15 years. His body mass index was $23.9 \mathrm{~kg} / \mathrm{m}^{2}$ and the patient reported an almost stable body weight over the last 15 years except for the 1-2 months before presentation. The most recent annual medical examination (May 2002) identified hypercholesterolemia (total cholesterol [TC], $8.04 \mathrm{mmol} / \mathrm{l}$; LDL, $4.16 \mathrm{mmol} / \mathrm{l})$, which had also been pointed out over several years, but had been left untreated. Other tests including plasma glucose level were normal. He was treated with atorvastatin $(10 \mathrm{mg} /$ day $)$ from June 2002. One month later, his TC level fell to $5.95 \mathrm{mmol} / \mathrm{l}$ and simultaneously measured plasma glucose at 2 hours after meal was $6.1 \mathrm{mmol} / \mathrm{l}$.

In October 2002, he suddenly started to feel thirsty, with loss of appetite and developed frequent cramps in the legs and arms. He also noted weight loss $(\sim 3 \mathrm{~kg})$ over a period of $1-2$ months. There were no obvious infection-related symptoms. He consulted his medical practitioner who found a postprandial plasma glucose level (30 min after lunch) of $29.8 \mathrm{mmol} / \mathrm{l}$ and $\mathrm{HbA}_{1 \mathrm{c}}$ of $11.5 \%$. A diagnosis of diabetes mellitus was made and the patient was referred to our hospital for further management. Plasma insulin was $21 \mathrm{pmol} / 1$ while anti-GAD antibody and urine ketones were negative. A diagnosis of type 2 diabetes was made and the patient was started on $1700 \mathrm{kcal} /$ day diet. One month later, the plasma glucose level ( $2 \mathrm{~h}$ after breakfast) was $25.1 \mathrm{mmol} / 1, \mathrm{HbA}_{1 \mathrm{c}}$ was $13.2 \%$, and immunoreactive insulin was $31 \mathrm{pmol} / \mathrm{l}$. Based on the lack of significant improvement of hyperglycemia by diet alone, we decided to treat him with a rapid-acting insulin injection before each meal. In addition, to exclude possible adverse effect of atorvastatin, we discontinued this medication (Fig. 1). After 2 months of insulin therapy, the plasma glucose level ( $3 \mathrm{~h}$ after breakfast) was 5.8

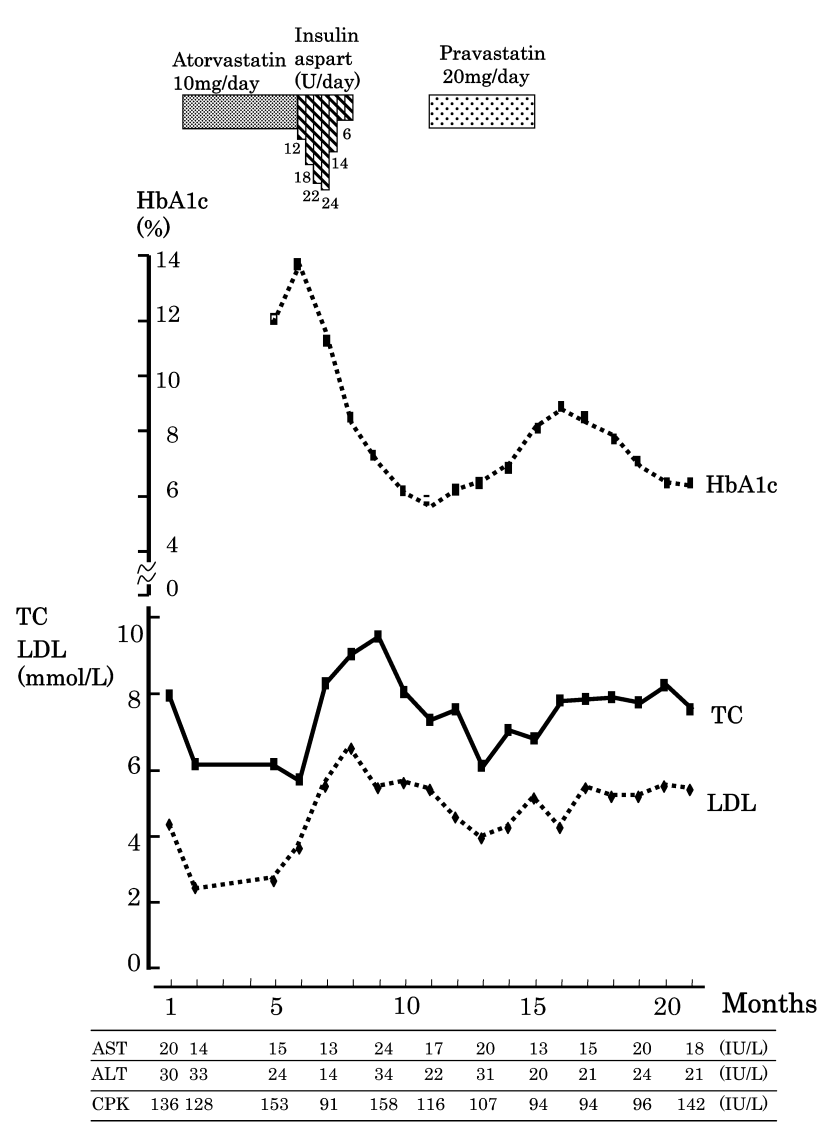

Fig. 1. Changes of $\mathrm{HbA}_{1 \mathrm{c}}$, lipid profile and laboratory data after commencement of atorvastatin treatment

$\mathrm{mmol} / \mathrm{l}$, immunoreactive insulin was $85 \mathrm{pmol} / \mathrm{l}$, and $\mathrm{HbA}_{1 \mathrm{c}}$ was $7.3 \%$. Without insulin, self-monitoring of blood glucose showed a preprandial plasma glucose level of $5.9 \pm 1.4 \mathrm{mmol} / \mathrm{l}$ and a 2 -h postprandial level of $10.0 \pm 2.1 \mathrm{mmol} / \mathrm{l}$. Thus, almost complete resolution of diabetes mellitus was observe at 12 weeks after the cessation of atrovastatin, so we discontinued insulin treatment.

During the subsequent 3 months, diet therapy alone was sufficient to control blood glucose level, though hypercholesterolemia was still present (fasting plasma glucose (FPG) was 6.0 mmol/1; $\mathrm{HbA}_{\mathrm{lc}} 6.0 \%$; TC 7.27 $\mathrm{mmol} / \mathrm{l}$; and LDL $5.17 \mathrm{mmol} / \mathrm{l})$. At that stage, we prescribed pravastatin $(20 \mathrm{mg}$ /day). Subsequently, serum cholesterol level 1.5 months later was modestly decreased, but $\mathrm{HbA}_{1 \mathrm{c}}$ was slightly increased (6.5\%). Then, diabetes worsened without obvious change of life style including food intake and physical activity and 4 months later, $\mathrm{HbA}_{1 \mathrm{c}}$ was $8.4 \%$; and FPG was $17.9 \mathrm{mmol} / \mathrm{l}$. One month after discontinuation of pravastatin, FPG decreased to $8.6 \mathrm{mmol} / \mathrm{l}$, and further 
decreased in the next month to $8.3 \mathrm{mmol} / \mathrm{l}$. Six months later, $\mathrm{HbA}_{1 \mathrm{c}}$ was $6.6 \%$ and FPG $5.4 \mathrm{mmol} / \mathrm{l}$. The blood glucose level was improved without using any drugs and obvious change of life style after discontinuation of pravastatin. In addition, throughout the whole clinical course, we did not observe any significant changes of serum AST, ALT, and CPK levels related to the administration of statins (Fig. 1).

\section{Discussion}

In the case presented here, the concurrence of administration of statins with onset and worsening of type 2 diabetes was observed. Of course, we cannot completely exclude the possibility that this was the natural course of the onset of diabetes. However, it seems more likely that atorvastatin promoted the development of diabetes in this case, because 1) the life style and state of health were unchanged around the date of onset of diabetes; 2) withdrawal of atorvastatin was clearly associated with the rapid resolution of diabetes with the aid of small doses of insulin over a short period; and 3) the administration and cessation of pravastatin were clearly associated with his blood glucose level.

In general, deterioration of diabetes largely depends on poor diet restriction and lack of exercise. Thus, little attention is paid to the possibility that statins might worsen diabetes. According to the epidemiological data, ASCOT-LLA trial showed that the percentage of subjects who developed diabetes among those treated with atorvastatin was higher than in the non-treated group, although the difference was not statistically significant [11]. The recently reported PROVE-IT TIMI 22 substudy identified that the treatment of atorva- statin was associated with a subtle increase in $\mathrm{HbA}_{1 \mathrm{c}}$ level. These data suggest that statins might have only a modest adverse effect on glucose tolerance in general population. However, considering the variation of drug sensitivity in each individual, it is possible that particular patients as shown in this report are sensitive to the adverse effect of statins.

Previous experimental data suggest that statins might deteriorate insulin secretion and insulin sensitivity [9, 10]. Thus, it is helpful for elucidating the main cause of type 2 diabetes in this case, to evaluate insulin secretion and insulin sensitivity under the administration of statins. However, once type 2 diabetes was developed, it is hard to elucidate them in general clinical setting. Considering the fact that prominent adverse effects of statins, though their frequency is rare, include myopathy and liver dysfunction [12], it is possible that an abnormality occurring in liver or muscle could cause a deterioration of glucose tolerance in this case. However, as far as assessed by general laboratory data, we could not find any obvious abnormality of muscle and liver (Fig. 1). Hence, we could not establish a possible link between general adverse effects of statins and their effect on glucose tolerance in this case.

This is the first case report exhibiting the possible association between the administration of statins and onset and worsening of diabetes. In the case described here, atorvastatin grossly and adversely affected glucose tolerance. However, when the effect is less evident, the adverse effects might be less noticeable or even unnoticeable altogether, unless one is aware of such adverse effect of statins. Considering the frequent prescription of statins, we believe that our case report will provide useful information for general physicians.

\section{References}

1. Sacks FM, Pfeffer MA, Moye LA, Rouleau JL, Rutherford JD, Cole TG, Brown L, Warnica JW, Arnold JM, Wun CC, Davis BR, Braunwald E (1996) The Effect of Pravastatin on Coronary Events after Myocardial Infarction in Patients with Average Cholesterol Levels. Cholesterol and Recurrent Events Trial Investigators. N Engl J Med 335: 1001-1009.

2. (1994) Randomised Trial of Cholesterol Lowering in 4444 Patients with Coronary Heart Disease: The Scandinavian Simvastatin Survival Study (4s). Lancet 344:
1383-1389.

3. Shepherd J, Cobbe SM, Ford I, Isles CG, Lorimer AR, MacFarlane PW, McKillop JH, Packard CJ (1995) Prevention of Coronary Heart Disease with Pravastatin in Men with Hypercholesterolemia. West of Scotland Coronary Prevention Study Group. N Engl J Med 333: 1301-1307.

4. Colhoun HM, Betteridge DJ, Durrington PN, Hitman GA, Neil HA, Livingstone SJ, Thomason MJ, Mackness MI, Charlton-Menys V, Fuller JH (2004) 
Primary Prevention of Cardiovascular Disease with Atorvastatin in Type 2 Diabetes in the Collaborative Atorvastatin Diabetes Study (CARDS): Multicentre Randomised Placebo-Controlled Trial. Lancet 364: 685-696.

5. Corsini A, Mazzotti M, Raiteri M, Soma MR, Gabbiani G, Fumagalli R, Paoletti R (1993) Relationship between Mevalonate Pathway and Arterial Myocyte Proliferation: In Vitro Studies with Inhibitors of HMGCoA Reductase. Atherosclerosis 101: 117-125.

6. Yamakawa T, Tanaka S, Kamei J, Kadonosono K, Okuda K (2003) Pitavastatin Inhibits Vascular Smooth Muscle Cell Proliferation by Inactivating Extracellular Signal-Regulated Kinases 1/2. J Atheroscler Thromb 10: 37-42.

7. Kearney D, Fitzgerald D (1999) The Anti-Thrombotic Effects of Statins. J Am Coll Cardiol 33: 1305-1307.

8. Marz W, Wieland H (2000) HMG-CoA Reductase Inhibition: Anti-Inflammatory Effects Beyond Lipid Lowering? Herz 25: 117-125.
9. Yada T, Nakata M, Shiraishi T, Kakei M (1999) Inhibition by Simvastatin, but Not Pravastatin, of GlucoseInduced Cytosolic Ca2+ Signalling and Insulin Secretion Due to Blockade of L-Type Ca2+ Channels in Rat Islet Beta-Cells. Br J Pharmacol 126: 1205-1213.

10. Chamberlain LH (2001) Inhibition of Isoprenoid Biosynthesis Causes Insulin Resistance in 3T3-L1 Adipocytes. FEBS Lett 507: 357-361.

11. Sever PS, Dahlof B, Poulter NR, Wedel H, Beevers G, Caulfield M, Collins R, Kjeldsen SE, Kristinsson A, McInnes GT, Mehlsen J, Nieminen M, O'Brien E, Ostergren J (2003) Prevention of Coronary and Stroke Events with Atorvastatin in Hypertensive Patients Who Have Average or Lower-Than-Average Cholesterol Concentrations, in the Anglo-Scandinavian Cardiac Outcomes Trial--Lipid Lowering Arm (ASCOT-LLA): A Multicentre Randomised Controlled Trial. Lancet 361: 1149-1158.

12. Tobert JA (1988) Efficacy and Long-Term Adverse Effect Pattern of Lovastatin. Am J Cardiol 62: 28J-34J. 